\title{
MI EXPERIENCIA DEL LAICADO BAJO LA ERA LANDÁZURI: ENTRE TESTIMONIO E HISTORIA
}

\section{MY EXPERIENCE ABOUT LAITY DURING LANDÁZURI'S ERA: BETWEEN TESTIMONY AND HISTORY}

Carlos Castillo Mattasoglio*

Escribo con gusto estas notas sobre el laicado en el ministerio de mi amigo el Cardenal Juan, no solo porque él acogió mi vocación laical, de cristiano comprometido con el pueblo y con la iglesia, y reconoció ese camino para volcarlo a favor de la vocación sacerdotal, sino también porque hasta hoy en mi vida la mayor parte de mis años todavía son como laico; solo cuando llegue a los 68 años tendré la mitad de mi vida como laico y la mitad como sacerdote, ya que el Cardenal Juan me impuso las manos el 15 de julio de 1984 a los 34 años.

Comienzo con unos elementos personales en relación al cardenal Juan. Yo toda mi vida cristiana consciente viví la iglesia bajo su gobierno, aunque del gobierno del Cardenal Guevara me quedaba solo una muy vaga idea amable por el trato que me daba mi tío Ignacio Arbulú Pineda, monseñor de la curia de Lima, que venía al Rímac a celebrar la misa y me regalaba hostias sin consagrar, con las que comencé a "jugar" a celebrar misa desde niño (3 años).
Más mayorcito, a los 9 años, en 1959 ingrese al colegio San Agustín y allí el Cardenal nos visitaba, lo mismo que en el colegio de Jesús de mi hermana. Su perfil de arzobispo de Lima era mencionado en todas las ceremonias del colegio. Además conservo un recuerdo durante el desfile militar de 1962 donde el presidente Prado entraba a la avenida Brasil desde la Javier Prado y Landázuri lo hacía desde la plaza Bolognesi, con todos sus atuendos de arzobispo y cardenal. Ya ese año se indicaba que habría un concilio, y que la iglesia haría cambios, cosa que comenzó en octubre de ese año.

Solo en 1964 y 1965, esa imagen se fue acercando personalmente, no solo porque en el colegio fuimos a recoger el premio de la colecta de las misiones, que él nos lo entregó en la Plaza de Armas junto al presidente Belaúnde, sino porque luego, en junio de 1965, fui a un retiro en el Seminario de Santo Toribio que fue decisivo para tomarme un tiempo y entender la diocesaneidad y mi propia vocación, a partir de lo

* Docente de la Pontificia Universidad Católica del Perú: ccastillomattasoglio@gmail.com El presente artículo es un testimonio que el P. Carlos Castillo, diocesano de Lima, ha escrito desde su experiencia del laicado bajo el tiempo en que conoció al Cardenal Juan Landázuri Ricketts. Es parte de una obra colectiva que se prepara en homenaje a los 100 años del nacimiento del gran Cardenal reformador de la Iglesia peruana de 1955 a 1989. 
cual, por obra de mi amigo seminarista Hugo Risco López Lavalle, gracias a su terca pero preciosa insistencia, entré en la Juventud Estudiantil Católica (JEC), asistiendo al campamento de febrero de 1966, siendo luego de ella militante, llegando a ser delegado de la JEC de Lima ante la Asamblea Episcopal Regional de las sedes de la metrópoli, con solo 16 años de edad, donde por fin lo conocí más directamente.

\section{El punto de partida: La Acción Católica, sus ramas, especializaciones y el Concilio Vaticano II.}

A partir de allí fui miembro del Consejo Arquidiocesano de la Acción Católica (AC), al que pertenecía la JEC, y fui invitado para una importante reunión sobre el tema del "Mandato" en los estatutos de la Acción Católica, y la diferencia entre los movimientos de la Acción Católica (General, parroquial, especializada y consorcios) y los nuevos movimientos del Apostolado Seglar (AS), que comenzaron a surgir en ese tiempo, favorecidos por la Decreto Conciliar Apostolicam Actuositatem (AA), que el cardenal Juan había ordenado que se aplicara, con la consideración de las particularidades de dichos nuevos movimientos y de la Acción Católica.

El ambiente estaba generado por el inicio de la aplicación del Concilio en la iglesia de Lima, del cual Landázuri fue fiel promotor. Landázuri, con su sencilla y humilde personalidad, suscitó apertura al dialogo y participación laical impresionante, donde todos, incluido yo, un mocoso de 16 años podía tomar la palabra, e incluso opinar dentro de asambleas de obispos.

Grato recuerdo guardo de aquella reunión, en 1966 de la Acción Católica en el local de Máximo Abril, donde conocí a los presidentes de la Acción Católica Nacional, Don Cesar Arróspide, su hermana doña Esther, a Miguel Vallier presidente de la Acción Católica de Lima, Jorge Alayza Grundy y su esposa, Alicia de Alayza, a Amparo Ferrer, a Inés Echecopar de la JIC, al P. Tadeo Fuertes asesor de la JARC, a Alberto Rutte de la UNEC, a Carlos Álvarez de la JOC, y nosotros de la JEC, que asistimos Chabuca Castro y yo. Además, a los dirigentes de los consorcios (oficinistas, educadores y químico farmacéuticos), recuerdo a uno, Pepe Baraona. Y todos reunidos bajo la asesoría del obispo auxiliar de Lima, Mons. Fidel Tubino. A todos ellos los conocí, siendo yo el más joven e impresionado por la calidad de personas formadas en la tradición de los movimientos en la AC Peruana, del que me honraba ser miembro, desde mi participación en el movimiento de la JEC, y luego, cuando entré a San Marcos, en la Unión Nacional de Estudiantes Católicos (UNEC).

El tema y la discusión del 66 era alrededor de la situación en que quedaba la AC, y el tema del "mandato" (AA.20) ahora que la AA había abierto más el radio, optando por la línea de desarrollo de un amplio apostolado seglar (AA 15-19); en efecto la AA. daba un trato especial a la AC con algunas "notas" que debía tener. Mientras se planteaba la constitución de una más amplia organización de los laicos, con la perspectiva planteada también por la AA.: el Apostolado Seglar. Las discusiones abarcaron todo el 66 y el 67, en el que se toma una decisión. Se acordó la apertura y en cierto sentido la "disolución" de la Acción Católica en el Apostolado Seglar, cosa, probablemente no muy adecuada, pero al fin y al cabo abierta a lo nuevo. Nada gustó a Mons. Tubino, que había sido antes de ser sacerdote y obispo auxiliar de Lima, 
presidente de la AC. Pero Landázuri la aprobó favoreciendo el reconocimiento de las iniciativas laicales y con un espíritu de mayor apertura y diálogo.

\section{La extensión a los movimientos de Apostolado Seglar y la preparación de Medellín}

Por ello, en esa línea pastoral, y en coordinación con la conferencia episcopal, se creó bajo la asesoría de Mons. José Dammert Bellido la coordinación de los movimientos de Apostolado Seglar, que incluía a los mencionados de la AC y a los nuevos movimientos, como el Movimiento Familiar Cristiano (MFC) (con Armando Tovar y Sra.), los Cursillos de Cristiandad (con Héctor Gallegos y el P. Muntaner), las Hermandades del Trabajo, las Congregaciones Marianas, y otras organizaciones laicas que sin duda ampliaban el radio del laicado, por lo menos un poco más, aunque no todo, lo que ocurrirá poco después. Se creó así, gracias al aliento de Landázuri, una instancia nacional y arquidiocesana llamada el Apostolado Seglar (AS), en donde estábamos representados todos los movimientos en condiciones paritarias.

Durante 1967, fui presidente nacional de la JEC, junto a Julio López Mas, y fui encargado de colaborar en este proceso de Apostolado Seglar debiendo asistir a las reuniones con toda esta amplia asamblea que constituía todo un sentir laical con peso en la Iglesia, y allí Mons José Dammert, delegado de la Asamblea Episcopal para el asunto laical, alentó la conformación de dicha asamblea, de modo que saneado el asunto de la relación entre la AC y demás movimientos, en un solo cuerpo de Apostolado Seglar, estuvimos en mejores condiciones para afrontar novedades que se venían produciendo y tomar iniciativas de diverso tipo. Sobre todo participar del enorme movimiento laical suscitado para preparar la realización de la iniciativa de los obispos de AL en el CELAM, quienes desde el Concilio habían pedido a Paulo VI adaptar a nuestra realidad el Concilio con todos aquellos puntos que en cierto modo quedaron inconclusos.

Landázuri, que preparaba ya Medellín, quiso que los laicos peruanos hiciéramos un aporte, y en medio de esta búsqueda de participación de los movimientos laicos del Perú, nos reunimos en Naña en Junio de 1968, un mes antes de la reunión de Medellín, con todo el grupo del AS, cuyas conclusiones se resumieron en dos textos decisivos para la historia posterior del laicado peruano: el "Documento de los movimientos de Apostolado Laico del Perú con ocasión de la Asamblea Episcopal de Medellín" y la "Declaración de laicos sobre la Iglesia", también de Junio de 1968. El primero manifestaba los ejes del compromiso de los laicos en el mundo latinoamericano, afectado estructuralmente por la pobreza debida a la injusticia, y en las estructuras eclesiales, su identidad y relación con la jerarquía; y el segundo manifestaba el modelo de Iglesia que debía construirse en el Perú, tomando el ejemplo comenzado por el propio Cardenal Juan:

"Los laicos adherimos sinceramente a ese movimiento de la Iglesia y por eso, en el Perú, hemos contemplado con satisfacción actitudes de la Jerarquía que revelan una profunda decisión de autenticidad evangélica. Basta recordar la postergación indefinida, dispuesta por nuestro cardenal Primado, de un dispendioso proyecto de basílica a Santa Rosa; o la declaración tajante de treinta y cinco sacerdotes, seguida de múltiples adhesiones y respaldada por el mismo prelado, denunciando 
como "una traición al desarrollo del Perú" no predicar la "riqueza doctrinal del Evangelio como una mística revolucionaria".

En efecto, Landázuri no sólo seguía el proceso de surgimiento del laicado de cerca, ni sólo estaba informado de todo, sino que lo alentaba haciendo signos y gestos que lo favorecieran, y pronunciando palabras contundentes que remecieran no solo la conciencia de los peruanos sino de todos los católicos y de algunos sectores de la propia jerarquía.

\section{Mi experiencia como laico en la JEC y la UNEC, la Parroquia universitaria y el compromiso con los pobres.}

Ese año de 1967, la apertura al laico era tal, que tuve la oportunidad de predicar en la primera misa juvenil que se realizó en Lima, en la Iglesia de Santa Beatriz, y que fue comentada en el diario el Comercio. Era la conclusión de una primera semana Juvenil que realizaron los muchachos de la parroquia de Lince, dirigidos por el laico Joven del colegio Melitón Carvajal, Víctor Méndez Villegas, gran amigo, invitándome como Jecista a que comentara el evangelio en el momento de la homilía, para invitar a los jóvenes a un compromiso con el desarrollo del país y haciendo suyas las necesidades de los pobres de nuestra patria. El padre párroco, que ya me había invitado a decir unas palabras en el funeral de mi hermano Ismael, hacía dos años antes (en 1965), deja que esto se realizara con entera libertad. Como todavía no se había normado la liturgia como hoy, los ensayos en liturgia permitieron la predicación de algunos laicos, así ya lo había hecho antes que yo don Miguel Vallier, presidente de la ACL.

Estos primeros pasos en mi laicado como joven, marcaron definitivamente mi vida, me infundieron un ferviente amor a la Iglesia, por lo cual, sintiendo ya el llamado a ser sacerdote al final de mis años de escolar, la inmensa labor laical y pastoral de Landázuri, en la que se insertaba la Iglesia toda en fidelidad al Concilio, y mucho más con las orientaciones de Medellín, me condujeron a prolongar mis años de un intenso compromiso como laico para ganar experiencia en la vida con el pueblo y, desde él, con la Iglesia. Me ayudó en ello ver cómo alentaba también a otros ambientes laicos menos cercanos al mío, como en el caso de mi hermano Augusto del MFC, que fui nombrado por él, años después, delegado laico a la conferencia de Puebla de 1979.

Por ello decidí estudiar Ciencias Sociales, y en san Marcos, desarrollando mi identificación con la inquietud social del evangelio y conociendo y viviendo el Pensamiento Social de la Iglesia, junto con la reflexión marcada por la Opción Preferencial por los Pobres, que aprendimos y vivimos juntos esta vez en mi comunidad militante católica universitaria, la UNEC (Unión Nacional de Estudiantes Católicos), con la compañía y asesoría de Gustavo Gutiérrez, Felipe Zegarra, Luis Fernando Crespo y Pedro de Guchtenerre, ahondando y reflexionando cada paso de nuestros compromisos y orándolos a la luz del evangelio y en la celebración sacramental, con una espiritualidad viva, encarnada e histórica, dinámica en el caminar de las vicisitudes humanas y sociales de nuestro pueblo. La Teología de la Liberación, conocida hoy mundialmente, no era más que eso, y nacía al calor de nuestro compromiso cristiano con los más pobres de nuestra patria, y nada se podía comparar con ese compromiso solidario.

Participé en la dirección de la Parroquia Universitaria que realizaba 
la misa semanal en la Iglesia de 'Jesús, José y María', en la esquina de Camaná y Moquegua, ayudando a la difusión y formación comprometida de los universitarios con conferencias de gran calidad. Allí trabajamos con Josefina Huamán, Edmundo León, Carlos Sarmiento, Javier Iguiñiz y otros amigos que, domingo a domingo, abríamos este espacio a la reflexión cristiana viva y comprometida.

Con los años, nos organizamos como universitarios para ayudar a las poblaciones marginadas que avanzaban en su presencia en la ciudad. Sin duda estuvimos entre aquellas afectadas por el terremoto de Huaraz de 1970, que no solo remeció la tierra sino también la conciencia social de toda una generación universitaria, que se dejó interpelar por la injusta pobreza del país y aprendió poco a poco la solidaridad, y fuimos formando grupos y movimientos estudiantiles de compromiso en las llamadas, -en esa época-, "barriadas", y que son nuestros "pueblos jóvenes" o barrios populares de Lima. San Marcos y la Católica fueron universidades en que la inquietud social crecía, y en donde además de una politización un tanto excesiva, existía lo más importante, el sincero amor y la solidaridad con que actuábamos, con sentido cristiano y evangélico. La vida entre los pobres marcó definitivamente nuestra manera de vivir la fe.

Landázuri siguió nuestro proceso de diversos modos, porque en la arquidiócesis se informaba en asambleas e instancias internas de lo que íbamos avanzando. Por ello el arzobispado fue un gran centro de reuniones pastorales de todo tipo. Mons. Bambarén y Mons. Germán Schmitz, dedicados a los pueblos jóvenes y a los movimientos laicos, nos visitaban y nos trataban de comprender y escuchaban nuestras ideas, proponiéndonos también ellos alternativas, sugerencias y líneas. No solían imponer nada, corregían sin mangonear, sugerían con razones adecuadas y justas, y ello por consejo del Cardenal Juan, siguiendo su estilo suscitador y alentador, lleno de profunda autoridad. Cuando fui presidente de la UNEC de Lima, tuve trato directo con ellos y con el mismo Cardenal, que se enorgullecía de haber sido "asesor de la célula de la UNEC de San Marcos". La UNEC había sido "su movimiento", durante su periodo franciscano antes del episcopado.

\section{La extensión definitiva: por un nuevo laicado del pueblo}

Cuando después de Medellín, y gracias a las iniciativas previas que venían haciéndose en el terreno pastoral por parte de Landázuri, como la Misión de Lima y la Misión Conciliar, explicadas en este mismo volumen por Matías Sibenaller, Jorge Álvarez y Jorge López, yo como laico abrí los ojos para darme cuenta que un gran movimiento laical, más amplio aun de lo que yo había conocido, se iba expandiendo en la iglesia, el laicado de los pobres, de los agentes pastorales populares. Landázuri aspiraba a que los laicos tuvieran una participación y protagonismo desde su propia realidad humana, sencilla y pobre, y confió en todos los que lo procuraban, instituyendo medios de formación para que ellos fortalecieran su fe y su calidad humana. En las parroquias, los laicos como sujetos se sentían en casa, no se sentían siervos sino amigos.

La confianza que nos tuvo Landázuri, a las élites de los movimientos, recogía una larga historia desde los inicios de siglo, en el perfil de un laico distinto al esquema pasivo que derivaba de Trento. Pero Landázuri apuntaba a más, 
al laico pobre de nuestros pueblos, especialmente de los pueblos jóvenes, como sujetos activos de su experiencia eclesial.

Desde allí, la idea del laicado se me fue ensanchando hacia la inmensidad. Por ejemplo, en el primer encuentro que se llamó "Encuentro de cristianos por una iglesia solidaria", cientos de agentes pastorales de base popular de la Lima de los barrios populares, que circundaban la ciudad chiquita y colonial, hoy los conos norte, sur y este, llenaron el Colegio Ricardo Palma de Surquillo, y luego de tres días, celebramos la misa final en la parroquia Jesús Obrero. El laicado eran ellos, y los obispos auxiliares del Cardenal nos acompañaron, junto a los sacerdotes misioneros de la Lima popular. Para esos laicos de nuestro pueblo sencillo, Landázuri había ordenado un obispo en una parroquia pobre de san Martín de Porres, a Luis Bambarén, e hizo lo propio con Mons. Germán Schmitz, quien venía de ser párroco en San Felipe, y que mostró ser un pastor infatigable, fiel, sencillo e inteligente, que supo comprender y vivir hondamente como obispo de la Vicaria 6 del cono sur de Lima.

Era toda esta gente nueva de la iglesia con sus laicos populares, los que por ejemplo recibieron al Cardenal Landazuri en aquella circunstancia fatídica para la Iglesia del Perú, en que el Gral. Artola tomó prisionero a Mons. Bambarén luego de celebrar solidariamente la misa por los fallecidos en la invasión de Ciudad de Dios. Nacía una iglesia viva, formada por los pobres que se hacían iglesia, que pesaban en la sociedad y en la jerarquía eclesial, y que defendían a sus obispos unidos al Cardenal Juan, que llegó al aeropuerto Jorge Chávez y subido en una butaca del hall central, se unía a la demanda de libertad que exigían los laicos para Mons. Luis Bambarén. Lejos de seguir el consejo de su auxiliar de no declarar, declaró y con claridad puso en jaque al gobierno que debió destituir pocos días después a aquél ministro del interior. Fue esta presencia concreta, en un laicado popular, la que hizo crecer los niveles de aceptación de la iglesia que llegaba a más del 95 \% durante décadas. Solo hoy encontramos bajones enormes a veces hasta el 50 o el $40 \%$.

\section{Mi compromiso laico en Cerro de Pasco y la compañía de German Schmitz acogida por Juan Landázuri}

Ultimé mi compromiso laical, primero en san Marcos hasta 1972 en que terminé la sociología, y luego de algunos trabajos a favor del laicado en Lima, como la bellísima experiencia del Movimiento Fe y Acción Solidaria, que concentró a todos los grupos de reflexión cristiana más organizados y basados en el Ver Juzgar - Actuar. En 1975 partí para ejercer mi carrera a Cerro de Pasco, donde viví como laico y profesor de la universidad Daniel Alcides Carrión durante cuatro años y medio. A esta estancia le llamé "mi primer seminario", porque pude compartir, con mineros y campesinos amigos, la lucha diaria por afrontar la vida, teniendo en cuenta la fe, en un mundo difícil e inhóspito, lleno de injusticia y miseria. Pero antes de irme a Cerro de Pasco le manifesté al cardenal Juan, por medio de Mons. Germán, que iba allá para adquirir suficiente hondura de experiencia con el Perú, antes de decidirme a entrar al seminario, pensando en que Jesús conocía demasiado bien a su pueblo, quizás durante 30 años, antes de salir a predicar.

Mons. Germán me dijo que él no era mi obispo, y que mi obispo era el Cardenal Juan, y que él serviría de nexo, para seguirme en estos años de "retiro" 
en medio de los mineros de Cerro. Como fueron cuatro años y medio, y yo venía a Lima alguna vez en cada año, sostenía largas conversaciones con Germán en Barranco, donde vivió un tiempo, o en San Felipe. Me trasmitía también lo que conversaba con el Cardenal acerca de mi camino. Nunca recriminó que yo anduviera por los andes para alimentar mi vocación, más bien solo me pedía que orara y formara en Cerro de Pasco una pequeña comunidad cristiana, por ello, junto con algunos amigos allá, sobre todo Isabel Gálvez y Florencio Marcelo Cóndor, hicimos una pequeño grupo de Revisión de Vida, que luego de mi partida se convirtió en comunidad. A la vez, hice amistad con los padres Combonianos que estaban allí de misioneros, el P. Ángel Ubiale y el P. Luigi Consonni, un excelente amigo. Con ellos formamos un grupo también ligado al CEAS, que llamamos CEAS minero, con la ayuda de Ernesto Alayza Mujica, encargado del CEAS, unido al CEAS campesino, para ver todos los problemas sociales de las comunidades campesinas de la zona. De modo que también Mons. Bambarén estaba al tanto de mi proceso de compromiso eclesial, informando al Cardenal del avance del CEAS en estos terrenos.

\section{La aceptación de mi laicado para el sacerdocio ordenado}

El Cardenal Juan valoró este camino, y cuando cumplí casi 5 años en Cerro me decido a entrar al seminario, Mons. Germán informó al Cardenal Juan de mi decisión en julio de 1979. Yo decidí ser sacerdote en abril de 1979, y había venido conversando con Germán desde inicios de ese año acerca de mi entrada al seminario. Pero él pensaba que, por ser mi vocación la de un adulto, sería mejor hacer unos estudios fuera del país, y me señaló que había visto que Hugo
Echegaray era un excelente teólogo, de la UNEC, formado en Lyon y ordenado por el Cardenal, y que me aconsejara con él. Fui donde Hugo que se preocupó en darme a conocer cómo eran los estudios fuera, en Europa. Mons. Germán me manifestó que la petición al Cardenal tenía que ser, "quiero entrar al seminario", y que el Cardenal decidiría cómo sería esa "entrada". Sin embargo, una tragedia se interpuso: Hugo Echegaray muere prematuramente, luego de llegar de la Asamblea Episcopal de Puebla, justamente ese año. Esto suspendió todas las ideas que teníamos acerca de donde estudiar, y no quedó más que la frase de Germán, "Eminencia quiero entrar al seminario".

Pero el Cardenal se había enterado de mis intenciones, por una indiscreción de mi hermano Jorge en el verano de 1979, quien haciéndose eco de una conversación telefónica que hice a mi madre desde Cerro de Pasco, en que le dije que estaba a punto de decidirme a ser sacerdote y que era probable que saliera fuera a estudiar, -en base a las conversaciones con Germán y con Hugo-, le dijo al Cardenal, que se encontraba unos días de descanso en Santa Rosa, -donde mi hermano tenía una casa también-, "va a ser cura y se va a Francia". Parece que ella lo contó a mis hermanos, y mi hermano hizo eco de lo que eran ideas sueltas, no habiendo nada preciso. Yo tomé mi decisión, bien pensada y segura, en abril, un poco antes de la muerte de Hugo, pero bajé a Lima en julio. Donde le manifesté a Mons. Germán, quien se lo dijo a Landázuri. Y éste dijo estar ya enterado, "y por qué a mí me ha llegado tan tarde la noticia directa, yo ya sabía por su hermano que me lo dijo en el verano en la playa de Santa Rosa, y además que iba a ir a Francia, pero a mí Francia no me gusta mucho, hay mucha obscenidad". 
Entonces en julio de 1979 me consigue Germán la cita y veo al Cardenal en el Arzobispado. Llegué y le digo: "Eminencia quiero entrar al seminario", y me responde: "por qué no me has dicho antes y me vengo a enterar por tu hermano; desde febrero yo ya sabía y me asusté de que hayas pensado en Francia, allí hay muchas cosas feas"; "yo también pienso que es mejor que estudies fuera, Germán me lo ha sugerido y yo creo que siendo mayor, tu vocación está madura y mucho más en todo lo que has vivido entre los pobres de Cerro de Pasco, y en la UNEC, pero me gusta más que vayas a Roma, donde yo personalmente puedo seguirte porque voy cada año por lo menos una vez, habla con Germán y con Mons. Augusto que estudió allá, y yo voy a llamar al Pio Latino para encontrarte plaza", y bueno, "a pesar de que no me dijiste antes, ...no sabes lo contento que estoy Carlos Gustavo, tu siempre desde chico me sonreías y me mirabas con buenos ojos" (eso lo decía porque en la mencionada asamblea regional, a mis 16 años lo había abrazado efusivamente, cuando nos vimos personalmente por primera vez (ise acordaba!).

Me siguió todos esos años en Roma con mucho cariño, no viviendo yo en el Pio Latino sino en el Pontificio Colegio Español de San José; y me condujo a matricularme en la Pontificia Universidad Gregoriana; pude sentir su profunda amistad durante los 8 años de mi vida como seminarista; nos visitaba a todos los que nos formábamos de Lima en Roma, e íbamos a comer al Polese o a la Taberna Giulia, vivimos momentos muy lindos pero también muy duros, sobre todo cuando se enfermó una vez en Roma, y luego ya ordenado cuando se convocó a la Conferencia Episcopal a sesionar en Roma para tratar acerca de la Teología de la Liberación del P. Gustavo, y que gracias a Dios se esclareció en su aporte e importancia con un interesante documento que los periódicos italianos titulaban "Wojtila y Landázuri salvan a Gutiérrez".

\section{La ordenación de un laico comprometido}

Me ordenó diacono en Pisa, en la Pieve de santa Giulia, en Caprona, cuyo párroco, don Severino Dianich, ilustre eclesiólogo italiano y amigo extraordinario, me había acogido allí todos los veranos, y a la que viajamos en automóvil con mis padrinos, Luiz Alberto Gómez de Souza y su esposa Lucía, el 16 de octubre de 1983, y me ordenó sacerdote el 15 de julio de 1984 en la Catedral de Lima, con los testigos de la UNEC y de Cerro de Pasco presentes, siendo presentado por mi hermano, el P. Gustavo Gutiérrez.

Terminada la imposición de manos, y ya revestido con la estola y la casulla me dijo: "lo logramos, ya eres sacerdote del Señor y para tu pueblo", y mi madre se quitó el anillo de matrimonio correspondiente a mi padre, lo dio primero a don Cesar Arróspide, mi padrino, y este lo entregó en nombre de mi papá al Cardenal, que preguntó "¿qué es esto?", mi madre le dijo, es el anillo de su padre, que llevamos Augusto y yo durante los 50 años de nuestro matrimonio, que cumplimos pocos meses antes de que él fallezca. El Cardenal Juan lo recibió emocionado en su mano y me lo puso en mi dedo anular de la mano derecha diciéndome: "recibe el anillo que tus padres han llevado fielmente más de 50 años, para que tú también seas fiel a Jesús y a la Iglesia", y me abrazó profundamente. Me reenvió a Roma luego de ordenado para terminar la Licenciatura en Teología y luego quiso que hiciera el Doctorado, el cual terminé y sustenté el 26 de mayo de 
1987, estando presente, como delegado personal suyo, Mons. Luis Bambarén.

\section{El regreso de Roma y mi misión sacerdotal con los pobres de la Tablada, en la UNEC y en la PUCP}

Le había prometido volver a Lima y llegué el 16 de junio de 1987. Esa promesa surgió como respuesta a una recomendación suya, "no te vayas a quedar allá, te vayan a ofrecer un puesto en el Vaticano, aquí te necesitamos, a quien más se le da, más se le exigirá", eran sus palabras. Mi respuesta en varias oportunidades, y está en mis cartas que le envié, fue, "regreso a Lima con la condición de que no me envíe a una parroquia de la high, porque el que llega de Roma debe ser un servidor no un sobrado, usted mismo me lo ha enseñado". En efecto, apenas llegué y lo visité, me dijo que me ponía en manos de Germán Schmitz, que había sido mi director espiritual y que era ahora el obispo de la vicaría sur de Lima. José Antonio Ubillús, mi primo, era su vicario, y me indicó que el Cardenal había pensado un nuevo proyecto pastoral para ampliar el trabajo en la parte alta de Villa el Salvador llamada Tablada de Lurín, en donde me destinaba junto al párroco, Tadeo Fuertes, y mi amigo Jorge López que por muchos años había sido párroco de San Juan Apóstol, (una parroquia surgida después del Concilio en la Av. Bolivar de Pueblo Libre, adonde después de la experiencia de la Parroquia Universitaria de la UNEC, íbamos los universitarios católicos). Con Jorge y Tadeo hicimos equipo y logramos un precioso e interesante trabajo, especialmente con los jóvenes de Tablada.

Y allí en Tablada, en que fui vicario parroquial dedicado a los jóvenes del 87 al 90, me encontré en mi primera comunidad parroquial, viva y llena de esperanza, con un laicado nuevo de Landázuri, surgido de la evangelización liberadora de aquellos años, gente trabajadora, sencilla, con gran formación de fe, con capacidad de anuncio del evangelio y autoridad humana y cristiana, entre el pueblo, y en medio de los peligros de una crisis gravísima dejada por el primer gobierno aprista y por el terrorismo galopante que seducía a la juventud. Fueron años "de plomo", en que debimos predicar la paz en medio de la violencia; y con una amplia evangelización dimos una dura pelea ensanchando la paz que fue ahogando la violencia entre los jóvenes, con iniciativas preciosas de la propia gente, como la de las Semanas Juveniles de Tablada, que Mons. Germán nos sugería acoger y fortalecer, aprendiendo de ellos, lo cual Landázuri aprobaba con beneplácito. Los frutos de la iglesia que no vi en Lima, desde que subí a Cerro de Pasco, en 1974, y que no pude percibir en mi tránsito hacia Roma, los pude ver macizos, vivos y dinámicos en Tablada, gracias al inmenso respeto que el Cardenal Juan tuvo por mi vocación.

Quiso también que pusiera al servicio de la pastoral mis conocimientos en teología, ayudando en la formación de esos laicos en los cursos de Teología y Catequesis, en esta vicaría, especialmente en VITA (Villa el Salvador y Tablada), pero quiso que fuera asesor de la UNEC y que enseñara en la PUCP, a la cual me incorporé en el segundo semestre de 1987, y en la que ya casi cumpliré 25 años, y donde tuvimos la gratísima experiencia de los Cursos de Teología de Verano, con todos los agentes pastorales de la ciudad que venían a formarse en la fe.

Lo invitamos a confirmar a los muchachos de la Tablada y vino en diciembre de 1988, luego de recibir a 
todos los catequistas de confirmación en su despacho, y quedándose con nosotros toda la tarde incluso a almorzar. También nos organizamos para apoyarlo en el segundo viaje del Papa Juan Pablo II, con nuestra Guardia Juvenil del Papa, y quedó contentísimo de nuestra participación junto a todos los jóvenes del sur.

\section{Conclusión}

Landázuri fue todo un pastor que dejó huella en el laicado, especialmente en el laicado popular, en los agentes pastorales populares de la década del 60-70 y 80, y que hoy son los padres de familia que ayudarán con la memoria de Landázuri a resucitar la Iglesia de la gran Lima que enfrenta nuevos retos globales, pero que recurre a la memoria para soñar su iglesia y el mundo evangelizado de los pobres que hoy Francisco realiza.

Landázuri no rechazó ninguno de estos laicados, pero fue muy consciente de que había que ir ampliando el radio y el horizonte, de modo que fue pasando del laicado de la Acción Católica al laicado de la especialización, del laicado de los movimientos de Acción Católica al laicado de los movimientos de Apostolado Seglar, y de este al laicado de los agentes pastorales del pueblo sencillo. Y este es el tipo de laico que más requiere una iglesia viva, aquel que en la vida y sufrimiento concreto del pueblo es testigo de la resurrección de Jesús, para hacer de todos, especialmente de los pobres, "agentes pastorales", es decir, sujetos cristianos conscientes y sencillos que anuncian con seriedad, belleza y alegría la Palabra del Señor, y construyen el Reino de Dios anticipadamente en esta tierra. Su apertura, o su negativa a cerrarse en una sola idea, fue la base de su fidelidad al proyecto de Jesús que ahora celebramos en sus 100 años de nacimiento.

En mi vida eso significó una nueva manera de ser ahora sacerdote, habiendo primero aprendido una nueva manera de ser laico, y que no se puede olvidar. No solo se necesita ser bautizado para ser ordenado sacerdote; además, cada día nuestra condición laical es de raíz, el sacerdocio laico de Jesús nos hace ser mejores servidores, sacerdotes ordenados y ministros que saben orientar a su pueblo desde sus luchas y problemas, desde su "olor ovejuno".

Landázuri tuvo esto y mucho más, porque viniendo de los sectores altos de la sociedad se hizo franciscano, y poco a poco se fue abriendo a ese pueblo porque lo sentía en lo más profundo de su ser. Un hombre de Dios nacido en nuestro pueblo al servicio de su pueblo, por obra del Dios que nos envía a servir en Jesús, un eco de su santidad misericordiosa. El Cardenal Juan Landázuri Ricketts me lo enseñó, junto a varios amigos sacerdotes que he mencionado en este texto, como don Gustavo, y doy testimonio de ello. 